\title{
KRAS mutation in adenocarcinoma of the gastrointestinal type arising from a mature cystic teratoma of the ovary
}

\author{
Yan Li ${ }^{1}$, Ruiguang Zhang ${ }^{2}$, Danzhen Pan ${ }^{1}$, Bangxing Huang ${ }^{1}$, Mixia Weng ${ }^{1}$ and Xiu Nie ${ }^{1 *}$
}

\begin{abstract}
Mature cystic teratomas $(\mathrm{MCT})$ in the ovary rarely undergo malignant transformation. Moreover, adenocarcinoma of the gastrointestinal type is much rarer. We present two cases of perimenopausal female pateints with mature cystic teratoma of single ovary, while local adenocarcinoma arising in the MCT. The malignancies showed immunohistochemical features of intestinal differentiation, such as strong positivity for CDX-2, villin and CK-20, and negativity for CK-7. Furthermore, the mutation analysis of molecular alteration revealed a KRAS gene mutation in the intestinal adenocarcinoma part, extending into benign intestinal-type epithelium linings. Yet the mutation was not present in the epidermal component of the teratoma. We present these as two unique cases of mucinous adenocarcinoma of the intestinal type arising from mature cystic teratoma. Moreover, we also submit that this KRAS mutation might contribute to identify malignant transformation of a MCT and suggest possible effect on targeted treatment decisions for anti-epidermal growth factor receptor (EGFR) therapy in metastasized patients.
\end{abstract}

Keywords: Ovary, Mature cystic teratoma, Malignant transformation, Adenocarcinoma, Intestinal type, KRAS mutation

\section{Background}

The most common tumor of ovary is mature cystic teratoma (MCT), which arises from germ cells and accounts for more than $20 \%$ of all ovarian tumors [1]. Malignant transformation of MCTs occurs in 1-2\% of all these tumors [2]. During the malignancies arising in the MCT, squamous cell carcinoma is the most common type [3], with adenocarcinomas comprising only $6.8 \%$ of the malignant changes $[4,5]$. Furthermore, adenocarcinomas of the gastrointestinal type are much less frequent. So far there have been few reports of adenocarcinoma of the gastrointestinal type in the ovary arising from an MCT [6-8].

We present two cases with similarity of primary adenocarcinoma of the gastrointestinal type likely arising in a mature cystic teratoma of the ovary. Either patient had no evidence of a primary tumor elsewhere by previous medical history or radiographic survey. After extensive histological examination, the cyst with adenocarcinoma

\footnotetext{
* Correspondence: niexiuyishi@126.com

'Department of Pathology, Union Hospital, Tongji Medical College, Huazhong University of Science and Technology, Wuhan, People's Republic of China

Full list of author information is available at the end of the article
}

was found in continuity with a benign cystic lesion, which seemed at first slightly thicker compared to the surrounding normal wall. Yet, the microscopic evaluation revealed this part of cyst covered by epithelium showing malignant transformation into carcinoma with clearly defined irregular glands infiltrating into the stroma. The immunohistochemical (IHC) staining of the malignant change showed strong positivity for cytokeratin-20 (CK-20), villin and caudal type homeobox transcription factor 2 (CDX-2), while negative for CK-7. Moreover, as a number of studies had proved Kirsten rat sarcoma viral oncogene homolog (KRAS) and v-Raf murine sarcoma viral oncogene homo$\log \mathrm{B} 1$ (BRAF) oncogene mutations are recognized biomarkers that predict lack of response to anti-epidermal growth factor receptor (EGFR) antibody therapies and are associated with a worse prognosis in patients with metastatic adenocarcinoma in colorectal cancer [9-11]. To investigate further treatment in case of recurrence and metastasis of intestinal carcinoma for those two patients, we evaluate molecular alteration on oncogene mutation in cysts carrying adenocarcinoma, which showed positive for KRAS mutation and the mutation was extended into the benign intestinal-type epithelium of the cyst. 
Thus, we conclude that the adenocarcinoma of intestinal type was likely arising from a mature cystic teratoma. We also submit that this KRAS mutation might be helpful in identifying malignant transformation of a MCT and suggest possible effect on targeted treatment decisions for anti-epidermal growth factor receptor (EGFR) therapy in metastasized patients.

\section{Case presentation}

The first patient was a 51-year-old perimenopausal female, gravida 3 , para 1 , who was admitted with occasional nausea, abdominal pain and bloating for the past few years. Her previous medical, surgical, gynecological, and family histories were all unremarkable, with regular menstrual cycle. A mass in the left adnexal region was found in a routine pelvic examination. Ultrasound scan revealed the presence of an approximately $6 \mathrm{~cm}$ complex cystic mass of the left ovary. And there were no abnormal findings of the uterus and right adnexae. The patient had slightly elevated serum level of only one tumor marker. Her carbohydrate atigen 19-9 (CA199) was elevated to 41.9 $\mathrm{U} / \mathrm{ml}$ (normal $<35 \mathrm{U} / \mathrm{ml}$ ), while the other serum tumor markers, including carcinoembrionic antigen (CEA), CA 125 , $\alpha$-fetoprotein(AFP), were all within the normal ranges.

An exploratory laparoscopy with frozen section of the left ovarian tumor was performed. After the result of frozen section confirming malignant change in MCT, the procedure was changed to a total hysterosalpingooophorectomy with $400 \mathrm{mg}$ intraperitoneal carboplatin. Appendectomy and omentectomy were also carried out. Postoperatively, the patient opted for adjuvant chemotherapy, consisting of 6 cycles of paclitaxel $\left(135 \mathrm{mg} / \mathrm{m}^{2}\right)$ and carboplatin (area under the curve [AUC] of 5). After adjuvant chemotherapy, the patient's CA199 went back to normal and a whole-body positron emission tomographic scan was performed, the result of which was negative. The patient remains free of disease 13 months following diagnosis.
Macroscopically, the left ovary contained a smooth cystic mass $(5.8 \mathrm{~cm} \times 4.5 \mathrm{~cm})$ filling with sebaceous material, hair and teeth. The wall was average $0.1 \mathrm{~cm}$ $0.3 \mathrm{~cm}$ thin. Most of the inner surface of the mass was smooth, and had partial thicking-like nodules lining a rough surface. The right ovary was $3.2 \mathrm{~cm} \times 1.2 \mathrm{~cm} \times$ $1.0 \mathrm{~cm}$ and otherwise unremarkable. The cervix contained 1 small mucous cyst, and the uterus contained 2 small leiomyomas $(0.8 \mathrm{~cm}-1.0 \mathrm{~cm}$ diameter).

The microscopic examination of the left ovarian mass revealed components of a classic mature teratoma (Figure 1A). Most inner surface of the cyst was covered by squamous epithelium while malignant glandular epithelium (Figure $1 \mathrm{~B}$ and $\mathrm{D}$ ) was arising in continuity with benign mucous epithelium. The tumor was clearly defined irregular glands with stroma invasion (Figure $1 \mathrm{C}$ and $\mathrm{E}$ ). Tumour cells showed IHC-positivity of CDX-2 (Figure 2A), CK-20 (Figure 2B), villin (Figure 2C). Moreover, the IHC analysis showed negativity of CK-7 (Figure 2D), oestrogen receptor (ER) and human epidermal growth factor 2 (HER2) (data not shown) in the adenocarcinoma part.

Genetic mutation was detected in various components of the tumor mass, including malignant adenocarcinoma, benign intestinal-type epithelium and the squamous epithelium of the mature cystic teratoma. EGFR inhibition-targeted therapy is a new biologic therapy for the treatment of metastatic colorectal cancer which is also adenocarcinoma of intestinal type $[9,10]$. KRAS was an oncogene whose mutation status is a prognostic factor for survival rate and predictive of response to EGFR inhibition-targeted therapy in intestinal adenocarcinoma [10-13]. BRAF [14,15] and EGFR (epidermal growth factor receptor) [16] genes, which are important co-factors of KRAS gene in the EGFR signaling pathway in the carcinogenesis, invasion and metastasis of colorectal cancers, also have prognostic value for patients with metastasis of adenocarcinoma. So we chose KRAS, BRAF and EGFR as targets of mutation detection. Interestingly, quantitative

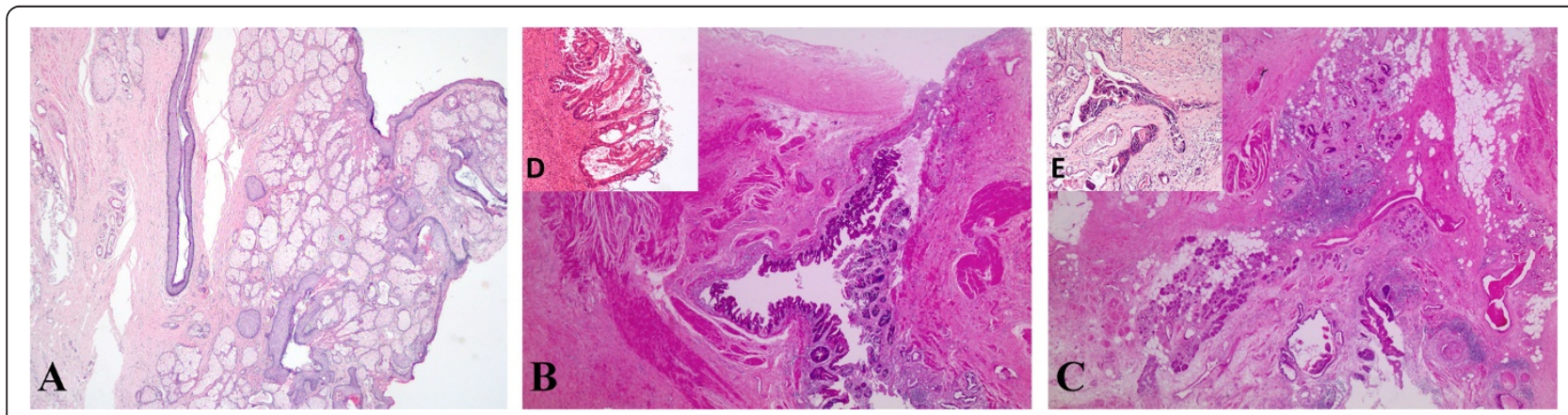

Figure 1 The microscopic examination of the left ovarian mass. A, Classic mature teratoma (haematoxylin - eosin, magnification x200); B, Malignant glandular epithelium was arising in continuity with benign mucous epithelium (haematoxylin - eosin, magnification x20); $\mathbf{C}$, Tumour infiltration in the stroma (haematoxylin - eosin, magnification x20); D, Magnified malignant glandular epithelium of B from the same field (haematoxylin - eosin, magnification x 100); E, Magnified intestinal-type adenocarcinoma in the stroma of C from the same field (haematoxylin - eosin, magnification x 100). 

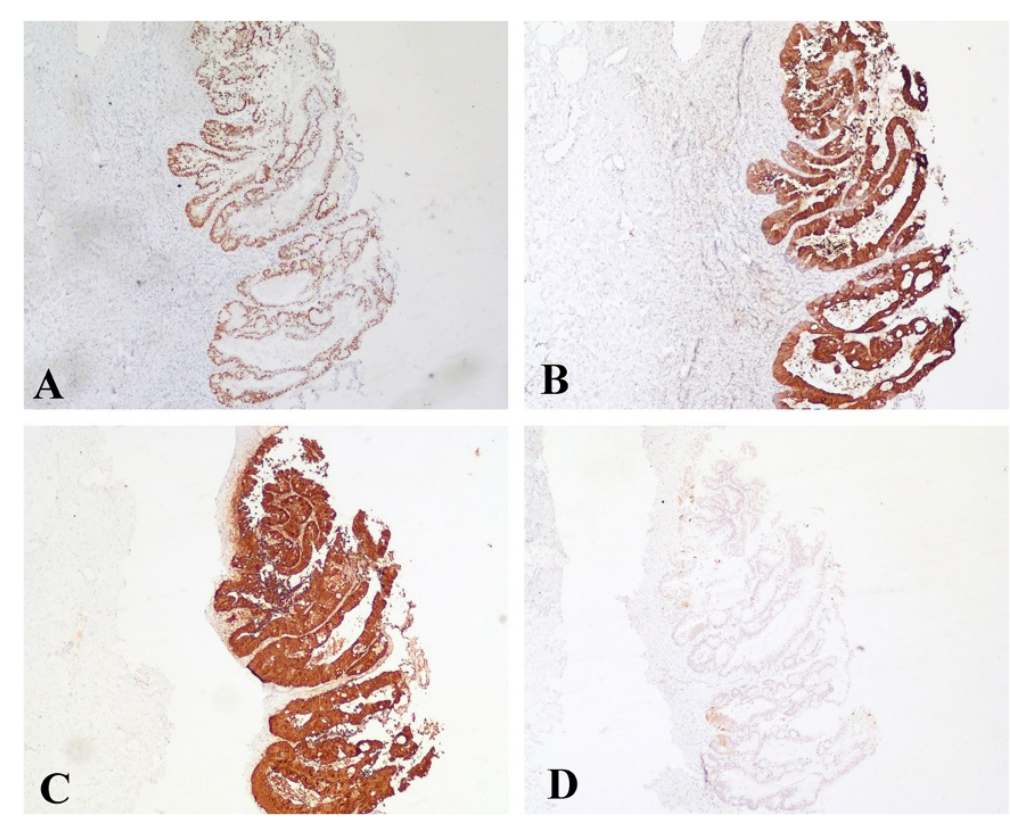

Figure 2 Immunohistchemical staining of the adenocarcinoma part arising from an ovarian teratoma. The adenocarcinoma part showed positive on CDX-2 (A), CK-20 (B) and villin (C) while CK-7 (D) was negative (magnification x 400).
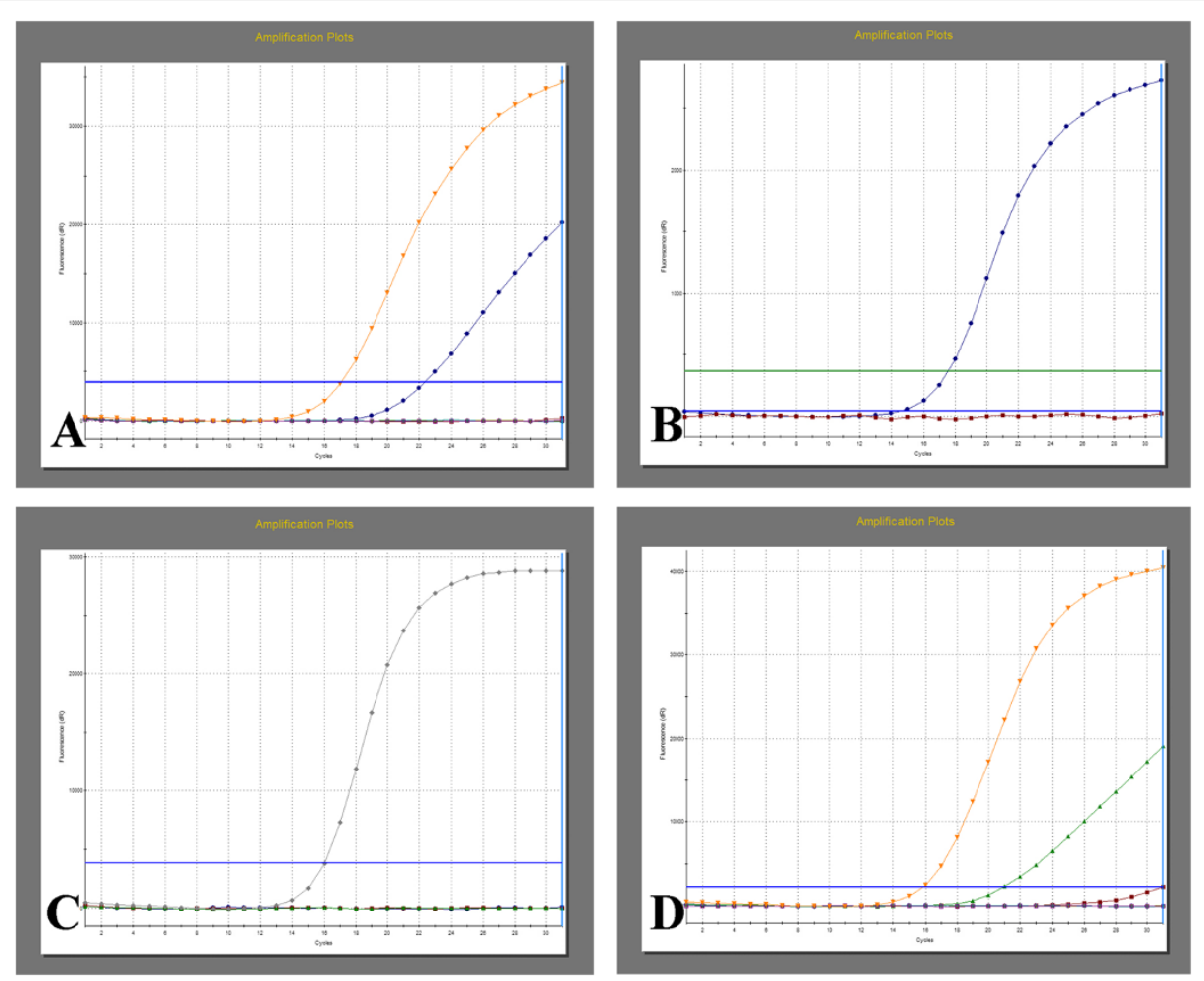

Figure 3 Mutation analysis revealed a KRAS mutation not only in the adenocarcinoma part but also benign intestinal-type epithelium linings. A, A mutation was found in codon 12 of the KRAS gene (NM_004985.3):C. 35G > T, p. (Gly12Val) in malignant glandular epithelium; B and C, There was no mutation in BRAF or EGFR genes in malignant glandular epithelium; $\mathbf{D}$, The same mutation was found in benign intestinal-type epithelium in the same patient. 
polymerase chain reaction (qPCR) revealed a mutation in codon 12 of the KRAS gene (NM_004985.3):c. 35G > $\mathrm{T}$, p. (Gly12Val) in both the intestinal adenocarcinoma (Figure 3A) and benign intestinal-type epithelium (Figure 3D), yet no mutation was found in squamous epithelium of the mature cystic teratoma (data not shown). Furthermore, no mutations were found in BRAF (Figure 3B) or EGFR (Figure 3C) genes in either part.

The other patient was a 43-year-old perimenopausal female, gravida 2, para 1, presented in September 2012 for a routine pelvic examination; an adnexal mass was found. Her case was in highly similar to the first case but harboring a different KRAS mutation in codon 12 of the KRAS gene (NM_004985.3):c. 34G > T, p. (Gly12Cys). We summarized the relevant clinical and pathological findings of all the previous reports on adenocarcinoma of the gastrointestinal type arising from MCTs of the ovary and presented in Table 1.

\section{Conclusions}

We present two cases with similarity of primary adenocarcinoma of the gastrointestinal type, harboring KRAS oncogene mutation, likely arising in a mature cystic teratoma of the ovary. As far as we know, these two cases are unique because currently there have been few report on teratoma-associated adenocarcinoma carrying KRAS oncogene mutation [1,4-8,21,22].

Malignant transformation of MCTs is a rare, often asymptomatic event which most commonly occurs in postmenopausal women. Also there have been plenty of varying reports on that, the risk of malignancy is estimated to be between $0.17-2 \%$ among all the transformations. As expected, any component of the MCTs might undergo malignant transformation, but most of the time (about $80 \%$ ) squamous epithelium is the most often prone to undergo malignant changes, which results in the squamous carcinoma [3]. Some less common malignancies include thyroid carcinomas [23], adenocarcinomas [1,4-7], or, less commonly, carcinoid tumors [24], mixed thyroid-carcinoid (struma carcinoid) [25].

The literature establishing adenocarcinoma of the gastrointestinal type is much rarer. To our knowledge, so far there have been only a few reports on it [4,6,7,17-19,21,22,26]. Although Kajo K et al. reported a case about mucinous carcinoma of non-intestinal type arising in the ovarian MCT [5], yet most of the previously described adenocarcinoma in MCTs showed characteristics of intestinal differentiation with immunohistochemical expression of CDX-2 and CK-20, and with negativity of CK-7 $[7,22]$. In present study, the immunohistochemical analysis showed positive staining in the CDX-2, CK-20 and villin, while the adenocarcinoma part was negative for CK-7, ER and HER2. The patient also underwent gastrointestinal endoscope to rule out the possibility of metastasis. Therefore, the diagnosis of present cases is adenocarcinoma of the intestinal type arising from a MCT.

The pathogenesis of mucinous adenocarcinoma arising from MCTs is somewhat different from that of colorectal cancer regarding clinical conditions. Morphology and

Table 1 Previous reports of adenocarcinoma of the gastrointestinal type arising from a MCT of the ovary

\begin{tabular}{|c|c|c|c|c|c|c|c|c|}
\hline Case & Source & Age & Tumor marker & $\begin{array}{c}\text { Tumor } \\
\text { size }(\mathrm{cm})\end{array}$ & $\begin{array}{l}\text { Surgical } \\
\text { procedure }\end{array}$ & $\begin{array}{l}\text { FIGO } \\
\text { stage }\end{array}$ & $\begin{array}{l}\text { Adjuvant } \\
\text { therapy }\end{array}$ & Follow up \\
\hline 1 & Ueda G et al. [4] & 62 & N.E. & 35 & $\mathrm{TAH}+\mathrm{BSO}$ & la & FAMT & 15 years \\
\hline 2 & Fishman A et al. [17] & 38 & $\begin{array}{c}\text { CEA: } 40 \mathrm{ng} / \mathrm{ml} \text { CA 125: } 80 \mathrm{U} / \mathrm{ml} \mathrm{CA153:} \\
60 \mathrm{U} / \mathrm{ml}\end{array}$ & $20 \times 13 \times 8.5$ & $\begin{array}{l}\mathrm{TAH}+\mathrm{BSO}+ \\
\mathrm{OMT}+\mathrm{APT}\end{array}$ & IIlc & $\begin{array}{c}5 \mathrm{FU} \\
\text { Leucovorin }\end{array}$ & $\begin{array}{l}\text { DOD } 3 \text { month } \\
\text { after surgery }\end{array}$ \\
\hline 3 & Kushima M [18] & 52 & $\begin{array}{c}\text { CA19-9: } 109 \mathrm{U} / \mathrm{ml} \text { SLX: } 58.5 \mathrm{U} / \mathrm{ml} \text { CA125: } \\
36 \mathrm{U} / \mathrm{ml} \mathrm{CA72-4:} 19 \mathrm{U} / \mathrm{ml}\end{array}$ & $\begin{array}{c}6.4 \times 4.8 \times \\
2.8\end{array}$ & Bilateral SO & la & none & 31 month \\
\hline 4 & Levine DA [19] & 37 & CEA: $11.2 \mathrm{ng} / \mathrm{ml} \mathrm{CA} \mathrm{125,} \mathrm{AFP,} \mathrm{HCG:} \mathrm{WNR}$ & $15 \times 12 \times 11$ & $\begin{array}{l}\text { Unilateral SO + } \\
\text { OMT + PLN + PAN }\end{array}$ & la & none & 40 month \\
\hline 5 & Guney M [20] & 38 & $\begin{array}{c}\text { CA1 25: } 99.1 \mathrm{U} / \mathrm{ml} \text { CA19-9 > } 1000 \mathrm{U} / \mathrm{ml} \\
\text { CEA: WNR }\end{array}$ & N.D. & $\begin{array}{c}\mathrm{TAH}+\mathrm{BSO}+ \\
\mathrm{OMT}+\mathrm{PLN}+\mathrm{PAN}\end{array}$ & la & none & N.D. \\
\hline 6 & Min KJ [6] & 77 & CA125: $72 \mathrm{U} / \mathrm{ml}$ & $17 \times 14 \times 2$ & $\mathrm{TAH}+\mathrm{BSO}$ & la & none & 12 month \\
\hline 7 & Takai M [7] & 49 & $\begin{array}{c}\text { CEA: } 6.9 \mathrm{ng} / \mathrm{ml} \text { CA 125: } 20 \mathrm{U} / \mathrm{ml} \text { CA19-9: } \\
3.8 \mathrm{U} / \mathrm{ml} \mathrm{SCC:} 1.1 \mathrm{ng} / \mathrm{ml}\end{array}$ & $6.7 \times 5.7$ & $\mathrm{TAH}+\mathrm{BSO}+\mathrm{OMT}$ & $\mathrm{Ic}(\mathrm{b})$ & none & 5 years \\
\hline 8 & Dov Hershkovitz [21] & 13 & $\begin{array}{l}\text { CA-19-9:162 U/ml CEA: } 5.5 \mathrm{ng} / \mathrm{ml} \\
\text { CA-125: } 268 \mathrm{U} / \mathrm{ml} \text { AFP, HCG: WNR }\end{array}$ & $7 \times 10$ & N.D. & la & N.D. & 5 month \\
\hline \multirow[t]{2}{*}{9} & Present case & 51 & $\begin{array}{c}\text { CA19-9: } 41.9 \mathrm{U} / \mathrm{ml} \text { CEA, CA 125, } \\
\text { AFP: WNR }\end{array}$ & $5.8 \times 4.5$ & $\begin{aligned} \mathrm{TAH} & +\mathrm{SO}+\mathrm{OMT} \\
& +\mathrm{APT}\end{aligned}$ & la & $P+C$ & 13 month \\
\hline & & 43 & $\mathrm{CA} 199>1200 \mathrm{U} / \mathrm{ml}$ & $10.8 \times 9.7$ & $\mathrm{TAH}+\mathrm{SO}$ & la & none & 11 month \\
\hline
\end{tabular}

1: TAH: total abdominal hysterectomy, SO: salpingo-oophorectomy, OMT: omentectomy, APT: Appendectomy, PLN: pelvic lymphadenecomy, PAN: para aortic 
immunophenotype of the intestinal type arising from a $\mathrm{MCT}$ are the same as in colorectal adenocarcinoma, more investigations are needed for further understanding pathogenesis particularly using molecular genetic analysis, like detection of mutation status. Although it has been claimed that colorectal adenocarcinoma is genetically similar to an intestinal-type adenocarcinoma in lung [20], so far there have been few reports on genetic comparison between colorectal adenocarcinoma and mucinous adenocarcinoma arising from MCTs. Reasons for the problem may be due to the limited case number and difficulty in separating the areas between the mucous components and adenocarcinoma part. Interestingly, recent studies on analysis of microsatellite polymorphism in mucinous ovarian carcinomas and associated teratomas showed a clonal match between the samples, suggesting that a subset of mucinous ovarian carcinoma actually arise from mature teratomas [27]. Fujii $\mathrm{K}$ et al. also demonstrated that the origin of the intestinal-type mucinous tumors might arise from mature cystic teratomas by microdissection and analysis of microsatellite markers [28]. Related studies gave us a clue to isolate different teratoma components and explore molecular genetic analysis.

It is difficult to make a diagnosis of malignant transformation of a MCT preoperatively. The patient's age, extremely enlarged mass in adnexal region by imaging and elevated tumor maker might remind the possibility of malignancy. In preset study, both patients were perimenopausal. Not only were the imaging results abnormal, but also the tumor maker CA199 elevated. Yet, extensive histological sampling was still crucial to reveal the carcinoma part, especially for local malignancy. In present cases, mutation analysis of molecular alterations showed a KRAS mutation in both the adenocarcinoma part and benign intestinal-type epithelium of the cyst. KRAS mutations were observed in $43 \%$ of ovarian carcinomas and in 30\% of colorectal carcinomas, which do not contribute to differential diagnosis in mucinous neoplasms of the colon and ovary [5]. Yet, mutation analysis might contribute to predict the malignant transformation in MCTs in case of under-diagnosis, especially for small lesion of malignancy. Moreover, the absence of KRAS mutation in the mature teratoma element in our samples suggests that this mutation accompanies with the intestinal-type epithelium.

The prognosis of patients with malignant transformation in MCTs is generally poor [29] and the majority of women die within a year after diagnosis [1]. The top affecting factor is tumor dissemination [30]. Thus, establishing an optimal therapeutic plan is important. So far, the treatment of choice for these tumors is surgery and there is little information on treatment outcomes of patients receiving chemotherapy directed to transformed histology given localized disease at presentation. Unfortunately, with tumors extending beyond the ovary, prognosis seems to be very poor. Dechaphunkul A et al. reported a case that a patient who achieved good response from chemotherapy directed to transformed histology, which confirms the importance of chemotherapy regimen used [31]. It brought us a new strategy of treatment by targeting at transformed histology. KRAS status is presently the only biomarker routinely used to select patients with colon cancer for EGFR inhibition-targeted therapy, which is widely used to treat metastatic colorectal cancer [32]. Thus we speculated if there was any chance for anti-EGFR antibody therapies after failure of first-line therapies, especially for metastasized patients. Further conclusions on selecting anti-EGFR antibody therapies need larger numbers of case studies and molecular genetic analysis in the intestinal-type adenocarcinoma arising from MCTs. Still, a risk and benefit discussion should be had with the patient, keeping in mind her age, comorbidities, surgical, and pathological findings.

Our case represents two unique cases of single ovarian MCT with malignant transformation to gastrolintestinal adenocarcinoma carrying KRAS mutation.

\section{Consent}

Written informed consent was obtained from the patient for publication of this Case Report and any accompanying images. A copy of the written consent is available for review by the Editor-in-Chief of this journal.

\section{Competing interests}

The authors declare that they have no competing interests.

\section{Authors' contributions}

$Y L$ and $R Z$ drafted the manuscript. DP performed the mutation analysis of molecular alteration. $\mathrm{BH}$ and $\mathrm{XN}$ examined microscopically surgical specimen. MW performed the immunohistochemical staining of the tumor. All authors read and approved the final manuscript.

\section{Acknowledgements}

This work was supported by the National Natural Science Foundation of China (grants 81200104 and 81302020) and Medical Scientific Research Foundation of Hubei Province (grant JX3B07). The funders had no role in study design, data collection and analysis, decision to publish, or preparation of the manuscript.

\section{Author details}

'Department of Pathology, Union Hospital, Tongji Medical College, Huazhong University of Science and Technology, Wuhan, People's Republic of China. ${ }^{2}$ Cancer Center, Union Hospital, Tongji Medical College, Huazhong University of Science and Technology, Wuhan, People's Republic of China.

Received: 7 March 2014 Accepted: 25 August 2014

Published online: 06 September 2014

\section{References}

1. Park JH, Whang SO, Song ES, Choi SJ, Lee WY: An ovarian mucinous cystadenocarcinoma arising from mature cystic teratoma with para-aortic lymph node metastasis: a case report. J Gynecol Oncol 2008, 19:275-278.

2. Peterson WF: Malignant degeneration of benign cystic teratomas of the overy; a collective review of the literature. Obstet Gynecol Surv 1957, 12:793-830 
3. Nor Azlin MI, Isa MR, Zaleha AM: Bilateral ovarian teratoma with squamous cell malignancy in a young woman: a diagnostic and management challenge. Int Med J 2005, 4:51-53.

4. Ueda G, Fujita M, Ogawa H, Sawada M, Inoue M, Tanizawa O: Adenocarcinoma in a benign cystic teratoma of the ovary: report of a case with a long survival period. Gynecol Oncol 1993, 48:259-263.

5. Kajo K, Masák L, Sorkovská D, Vallová M, Kajo M, Macháleková K, Helipianská L: Mucinous carcinoma (non-intestinal type) arising in the ovarian mature cystic teratoma - a case report. Cesk Patol 2013, 49:141-145.

6. Min KJ, Jee BC, Lee HS, Kim YB: Intestinal adenocarcinoma arising in a mature cystic teratoma of the ovary: a case report. Pathol Res Pract 2006, 202:531-535.

7. Takai M, Kanemura M, Kawaguchi H, Fujiwara S, Yoo S, Tanaka Y, Tsunetoh S, Terai Y, Yamada T, Ohmichi M: Mucinous adenocarcinoma of the intestinal type arising from mature cystic teratoma of the ovary: a rare case report and review of the literature. J Ovarian Res 2012, 5:41-46.

8. Vang R, Gown AM, Zhao C, Barry TS, Isacson C, Richardson MS, Ronnett BM: Ovarian mucinous tumors associated with mature cystic teratomas: morphologic and immunohistochemical analysis identifies a subset of potential teratomatous origin that shares features of lower gastrointestinal tract mucinous tumors more commonly encountered as secondary tumors in the ovary. Am J Surg Pathol 2007, 31:854-869.

9. Tol J, Punt $\mathrm{CJ}$ : Monoclonal antibodies in the treatment of metastatic colorectal cancer: a review. Clin Ther 2010, 32:437-453.

10. Yeung Y, Tebbutt NC: Bevacizumab in colorectal cancer: current and future directions. Expert Rev Anticancer Ther 2012, 12:1263-1273.

11. Lièvre A, Bachet JB, Le Corre D, Boige V, Landi B, Emile JF, Côté JF, Tomasic G, Penna C, Ducreux M, Rougier P, Penault-Llorca F, Laurent-Puig P: KRAS mutation status is predictive of response to cetuximab therapy in colorectal cancer. Cancer Res 2006, 66:3992-3995.

12. Heinemann V, Stintzing S, Kirchner T, Boeck S, Jung A: Clinical relevance of EGFR- and KRAS-status in colorectal cancer patients treated with monoclonal antibodies directed against the EGFR. Cancer Treat Rev 2009, 35:262-271.

13. Roth AD, Tejpar S, Delorenzi M, Yan P, Fiocca R, Klingbiel D, Dietrich D, Biesmans B, Bodoky G, Barone C, Aranda E, Nordlinger B, Cisar L, Labianca R, Cunningham D, Van Cutsem E, Bosman F: Prognostic role of KRAS and BRAF in stage II and III resected colon cancer: results of the translational study on the PETACC-3, EORTC 40993, SAKK 60-00 trial. J Clin Oncol 2010, 28:466-474.

14. Saridaki Z, Tzardi M, Sfakianaki M, Papadaki C, Voutsina A, Kalykaki A, Messaritakis I, Mpananis K, Mavroudis D, Stathopoulos E, Georgoulias V Souglakos J: BRAFV600E mutation analysis in patients with metastatic colorectal cancer (mCRC) in daily clinical practice: correlations with clinical characteristics, and its impact on patients' outcome. PLoS One 2013, 8:e84604.

15. Li WQ, Kawakami K, Ruszkiewicz A, Bennett G, Moore J, lacopetta B: BRAF mutations are associated with distinctive clinical, pathological and molecular features of colorectal cancer independently of microsatellite instability status. Mol Cancer 2006, 5:2.

16. Huang CW, Tsai HL, Chen YT, Huang CM, Ma CJ, Lu CY, Kuo CH, Wu DC, Chai CY, Wang JY: The prognostic values of EGFR expression and KRAS mutation in patients with synchronous or metachronous metastatic colorectal cancer. BMC Cancer 2013, 13:599.

17. Fishman A, Edelstein E, Altaras M, Beyth Y, Bernheim J: Adenocarcinoma arising from the gastrointestinal epithelium in benign cystic teratoma of the ovary. Gynecol Oncol 1998, 70:418-420.

18. Kushima M: Adenocarcinoma arising from mature cystic teratoma of the ovary. Pathol Int 2004, 54:139-143.

19. Levine DA, Villella JA, Poynor EA, Soslow RA: Gastrointestinal adenocarcinoma arising in a mature cystic teratoma of the ovary. Gynecol Oncol 2004, 94:597-599.

20. Stojsic J, Kontic M, Subotic D, Popovic M, Tomasevic D, Lukic J: Intestinal type of lung adenocarcinoma in younger adults. Case Rep Pulmonol 2014, 2014:282196.

21. Hershkovitz D, Vlodavsky E, Simon E, Ben-Izhak O: KRAS mutation positive mucinous adenocarcinoma originating in mature ovarian teratoma: case report and review of literature. Pathol Int 2013, 63:611-614.

22. Chang $\mathrm{J}$, Liu KY, Kuo $Y L$, Lee $W H$ : Adenocarcinoma arising from mature cystic teratoma of the ovary. J Med Sci 2002, 22:239-244
23. Cymbaluk-Ploska A, Chudecka-Głaz A, Chosia M, Ashuryk O, Menkiszak J: Conservative treatment of a young patient with thyroid carcinoma in adult ovarian teratoma - case report. Gynecol Endocrinol 2014, 30:187-191.

24. Sun K, You Q, Zhao M, Yao H, Xiang H, Wang L: Concurrent priomary carcinoid tumor arising within mature teratoma and clear cell renal cell carcinoma in the horseshoe kidney: report of a rare case and review of the literature. Int J Clin Exp Pathol 2013, 6:2578-2584.

25. Hinshaw HD, Smith AL, Desouki MM, Olawaiye AB: Malignant transformation of a mature cystic ovarian teratoma into thyroid carcinoma, mucinous adenocarcinoma, and strumal carcinoid: a case report and literature review. Case Rep Obstet Gynecol 2012, 2012:269489.

26. Guney M, Oral B, Demir F, Ozsoy M, Kapucuoglu N: Mucinous adenocarcinoma arising from the gastrointestinal epithelium in benign cystic teratoma of the ovary-case report. Eur J Gynaecol Oncol 2006, 27:304-306.

27. Kerr SE, Flotte AB, McFalls MJ, Vrana JA, Halling KC, Bell DA: Matching maternal isodisomy in mucinous carcinomas and associated ovarian teratomas provides evidence of germ cell derivation for some mucinous ovarian tumors. Am J Surg Pathol 2013, 37:1229-1235.

28. Fujii K, Yamashita Y, Yamamoto T, Takahashi K, Hashimoto K, Miyata T, Kawai K, Kikkawa F, Toyokuni S, Nagasaka T: Ovarian mucinous tumors arising from mature cystic teratomas-a molecular genetic approach for understanding the cellular origin. Hum Pathol 2014, 45:717-724.

29. Sakuma M, Otsuki T, Yoshinaga K, Utsunomiya H, Nagase S, Takano T, Niikura H, Ito K, Otomo K, Tase T, Watanabe Y, Yaegashi N: Malignant transformation arising from mature cystic teratoma of the ovary: a retrospective study of 20 cases. Int J Gynecol Cancer 2010, 20:766-771.

30. Arora DS, Haldane S: Carcinosarcoma arising in a dermoid cyst of the ovary. J Clin Pathol 1996, 49:519-521.

31. Dechaphunkul A, Bigras G, Sawyer M: Response to 5-Fluorouracil-based chemotherapy in a patient with metastatic colonic-type adenocarcinoma arising in a primary mediastinal teratoma. Case Rep Oncol Med 2012, 2012:729278.

32. Linardou H, Dahabreh IJ, Kanaloupiti D, Siannis F, Bafaloukos D, Kosmidis P, Papadimitriou CA, Murray S: Assessment of somatic k-RAS mutations as a mechanism associated with resistance to EGFR-targeted agents: a systematic review and meta-analysis of studies in advanced non-small-cell lung cancer and metastatic colorectal cancer. Lancet Oncol 2008, 9:962-972.

doi:10.1186/s13048-014-0085-3

Cite this article as: Li et al:: KRAS mutation in adenocarcinoma of the gastrointestinal type arising from a mature cystic teratoma of the ovary. Journal of Ovarian Research 2014 7:85.

\section{Submit your next manuscript to BioMed Central and take full advantage of:}

- Convenient online submission

- Thorough peer review

- No space constraints or color figure charges

- Immediate publication on acceptance

- Inclusion in PubMed, CAS, Scopus and Google Scholar

- Research which is freely available for redistribution 